\title{
Improvements of trapezoid antenna gain using artificial magnetic conductor and frequency selective surface
}

\author{
Siti Adlina Md Ali, Maisarah Abu, Siti Normi Zabri \\ Centre for Telecommunication Research and Innovation (CeTRI), Fakulti Kejuruteraan Elektronik \& Kejuruteraan \\ Komputer (FKEKK), Universiti Teknikal Malaysia Melaka (UTeM), Malaysia
}

\begin{tabular}{l} 
Article Info \\
\hline Article history: \\
Received Jan 13, 2020 \\
Revised Mar 15, 2020 \\
Accepted Apr 19, 2020 \\
\hline
\end{tabular}

Keywords:

Antenna

Artificial magnetic conductor

Frequency selective surface

Gain

Radiation pattern

\begin{abstract}
This paper presents the performance enhancement of the trapezoid antenna with Artificial Magnetic Conductor (AMC) and Frequency Selective Surface (FSS). The antenna, AMC and FSS structures are printed on $0.254 \mathrm{~mm}$ of RT/Duroid 5880 high frequency laminate. The performances of the antenna with and without AMC and FSS were evaluated. Three cases are analyzed; antenna alone, antenna with AMC and antenna with AMCFSS. The $2 \times 3$ arrays of AMC and AMC-FSS were positioned at the back of the antenna with $6 \mathrm{~mm}$ air gap. The antenna alone works at $12 \mathrm{GHz}$, and shifted to $12.35 \mathrm{GHz}$ and $12.33 \mathrm{GHz}$ for case 2 and case 3, respectively. Despite the shift in the resonance, the antenna is still operating well at 12 $\mathrm{GHz}$ with a return loss $-16.70 \mathrm{~dB}$ for case 2 and $-16.84 \mathrm{~dB}$ for case 3 . Case 3 effectively enhanced the antenna gain from $4.43 \mathrm{~dB}$ to $6.74 \mathrm{~dB}$ and contributed to a directive antenna. Moreover, case 3 also successfully reduced the radiation of the antenna that penetrates into human body as the antenna is applied for on-body applications.
\end{abstract}

Copyright (C) 2020 Institute of Advanced Engineering and Science. All rights reserved.

\section{Corresponding Author:}

Siti Adlina Md Ali,

Centre for Telecommunication Research and Innovation (CeTRI),

Fakulti Kejuruteraan Elektronik \& Kejuruteraan Komputer (FKEKK),

Universiti Teknikal Malaysia Melaka (UTeM), Hang Tuah Jaya 76100, Melaka, Malaysia.

Email: p021810003@ student.utem.edu.my

\section{INTRODUCTION}

Research in wideband and flexible antennas have received remarkable interest. Design of small, light-weight and conformable antennas are part of considerations in the design process [1-4]. Thus retain a good radiation efficiency and at the same time support large enough bandwidth to accompany the requirements of high data rates in modern communication systems are certainly more desirable and have become increasingly studied [5-8]. Antennas experienced performance degradation, i.e. frequency detuning, bandwidth reduction and radiation distortions as placed on human body [9-12]. Moreover, the radiation that penetrates into the human cells is a major health concern [13-15]. Metamaterials such as Artificial Magnetic Conductor (AMC) and Frequency Selective Surface (FSS) were first used due to its ability to increase gain and improve the radiation performances of the antenna [16-19].

Both AMC and FSS exhibit the properties of the zero-degree reflection phase of perfect magnetic conductor (PMC) at resonant [20-22]. A perfect electric conductor (PEC) is typically used as a reflector to enable antenna radiation to focus in one direction. However, the use of PEC produces an image current that flows in the opposite direction relative to the original current. The image current will interfere with the original current, thereby attenuating or even cancelling the latter and consequently degrading the radiation efficiency.

Interestingly, the image current problem can be solved by utilizing a PMC, which produces an image current in the same direction to the original current as illustrated in Figure 1. This implies that the reflection phase is $0^{\circ}$ and the magnitude of reflection coefficient, $\Gamma$, equals +1 . However, a PMC does not 
exist in nature, so an AMC can be designed only within a limited frequency band. AMC behaves like a PMC in the designed band, while it exhibits PEC characteristics in other bands [23-25].

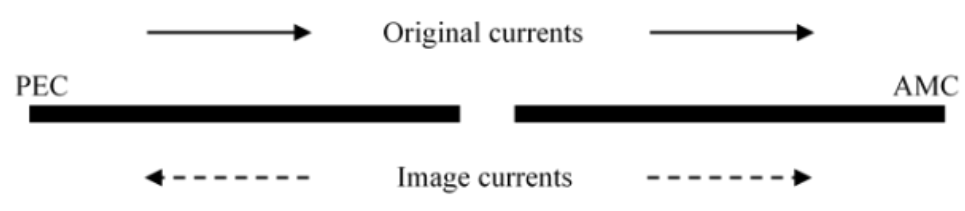

Figure 1. Trapezoid antenna design operating at $12 \mathrm{GHz}$.

This paper presents the performance enhancement of the antenna when incorporate with AMC, FSS and AMC-FSS. All of the structures were printed on $0.254 \mathrm{~mm}$ RT/Duroid 5880. The antenna is initially resonated at $12 \mathrm{GHz}$. The frequency shifted to $12.35 \mathrm{GHz}$ and $12.33 \mathrm{GHz}$ as the antenna incorporates with AMC and AMC-FSS respectively. The realized gain of the antenna alone is $4.43 \mathrm{~dB}$. It is enhanced to 9.73 $\mathrm{dB}$ when the antenna incorporates with AMC-FSS structure.

\section{RESEARCH METHOD}

This paper starts with the design of trapezoid antenna, AMC and FSS. The three structures are printed on an RT/Duroid 5880 substrate laminated with $0.035 \mathrm{~mm}$ Perfect Electric Conductor (PEC). The thickness and permittivity of the substrate are $0.254 \mathrm{~mm}$ and 2.2 respectively.

Figure 1 shows the geometry of the proposed antenna design where a trapezoidal patch is introduced the end of the two rectangular patches at both left and right sides which are connected with a $50 \Omega$ SMA connector as shown in Figure 2. The antenna' s performances are evaluated based on Return Loss (RL), Mismatch Loss (ML) and Voltage Standing Wave Ratio (VSWR).

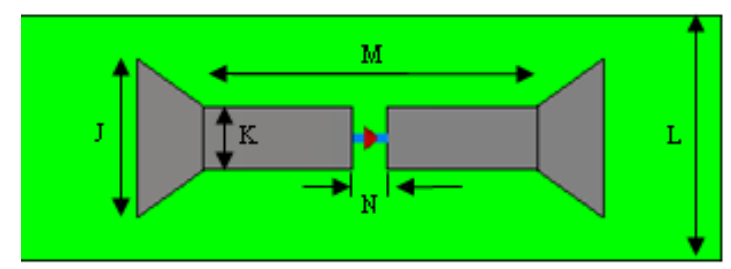

Figure 2. Trapezoid antenna design operating at $12 \mathrm{GHz} .(J=9.04 \mathrm{~mm}, K=3.63 \mathrm{~mm}, L=14 \mathrm{~mm}, M=18.96$ $\mathrm{mm}, N=2 \mathrm{~mm})$

Figure 3 shows the unit cell of an AMC which was designed based on trapezoid slot shape. The structure is built with three layers configurations; patch, substrate and ground. The AMC is developed using $1 \mathrm{~mm}$ trapezoid shape which is slotted on a $7.79 \mathrm{~mm}$ square PEC. Then it is printed on $10 \mathrm{~mm}$ square of $0.254 \mathrm{~mm}$ thick RT 5880 substrate. FSS is constructed using two layers configurations; a patch and a substrate. A ring shape is printed on the top layer with no metal laminated on the $0.254 \mathrm{~mm}$ thick RT 5880 substrate as shown in Figure 4.
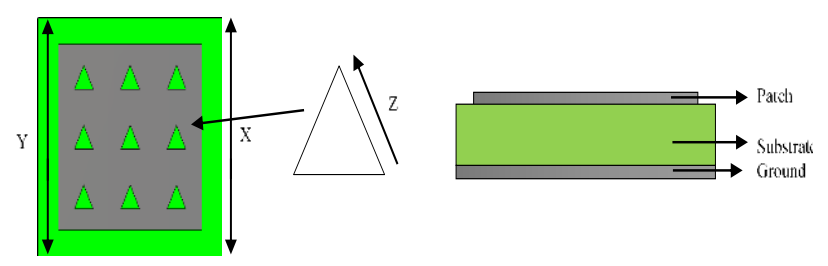

Figure 3. A unit cell of an AMC operating at 12 GHz. $(X=10 \mathrm{~mm}, Y=7.79 \mathrm{~mm}, Z=1 \mathrm{~mm})$
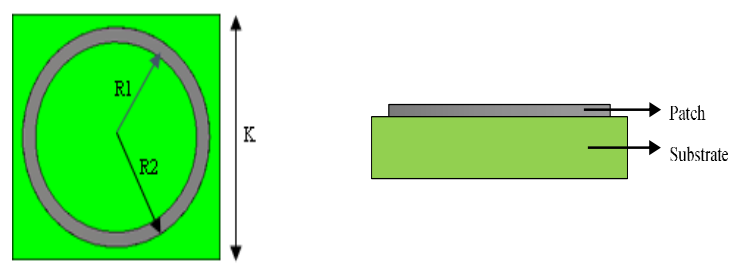

Figure 4. A unit cell of FSS operating at 12 GHz. $\left(K=10 \mathrm{~mm}, R_{l}=3.88 \mathrm{~mm}, R_{2}=4.50 \mathrm{~mm}\right)$ 


\section{RESULTS AND ANALYSIS}

The trapezoid antenna, AMC and FSS are initially characterized. The antenna is characterized with return loss $(\Gamma)$, mismatch loss (ML) and voltage standing wave ratio (VSWR). The unit cell of AMC is considered the reflection magnitude. Followed by the unit cell of FSS which is explained by the transmission coefficients. The realized gain of the trapezoidal shaped antenna is also takes to account as the antenna was incorporated with the AMC and FSS at the final stage. The antenna resonates at $12 \mathrm{GHz}$ with $-27.35 \mathrm{~dB}$ return loss as shown in Figure 5. The frequency lies between $11.33 \mathrm{GHz}$ to $12.63 \mathrm{GHz}$, contributed to bandwidth $1.30 \mathrm{GHz}$ approximately to $10.79 \%$ of. The calculated values of $\Gamma$, ML and VSWR are 0.043 , 0.008 and 1.090 , respectively.

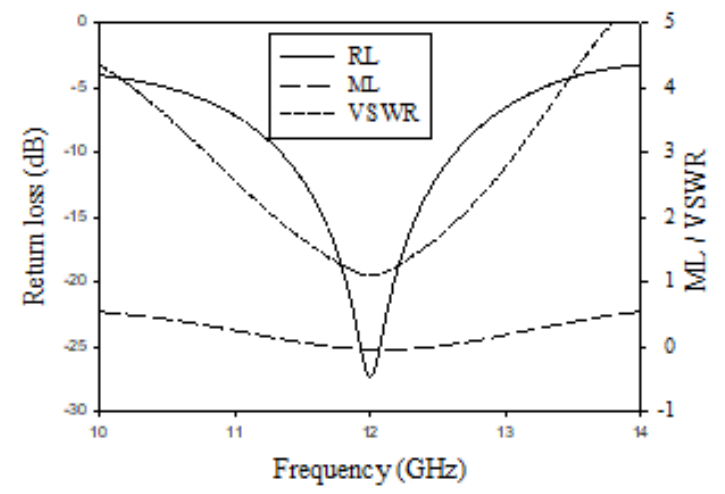

Figure 5. Performances of the trapezoid shaped antenna at $12 \mathrm{GHz}$.

Figure 6 and Figure 7 show the reflection phase of a unit cell of an AMC and the transmission coefficient of a unit cell of FSS respectively. The unit cell of AMC resonates at $12 \mathrm{GHz}$ with the reflection phase is varies from $-180^{\circ}$ to $180^{\circ}$. The useful bandwidth is $3.75 \%$, evaluated based on $\pm 90^{\circ}$ of reflection phase. Meanwhile, the transmission of the FSS unit cell is $-48.46 \mathrm{~dB}$ operating at $12 \mathrm{GHz}$. Thus contributed to $8.06 \mathrm{GHz}$ bandwidth, which is $67.16 \%$.

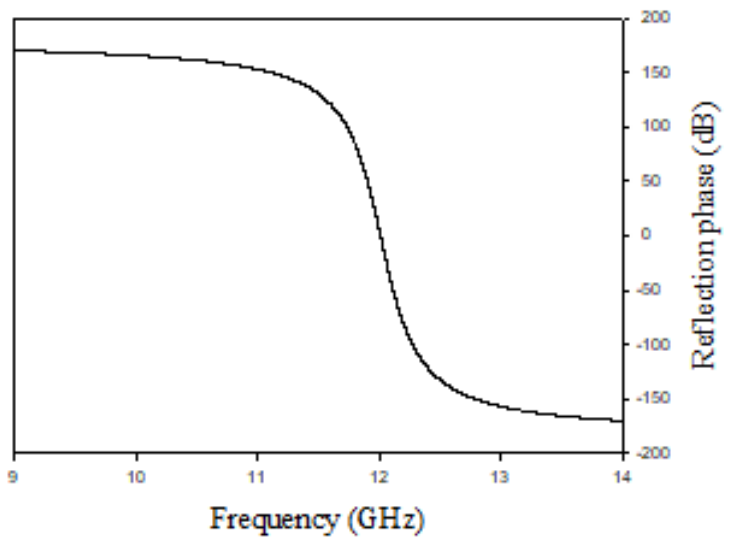

Figure 6. Reflection phase of a unit cell of AMC operating at $12 \mathrm{GHz}$

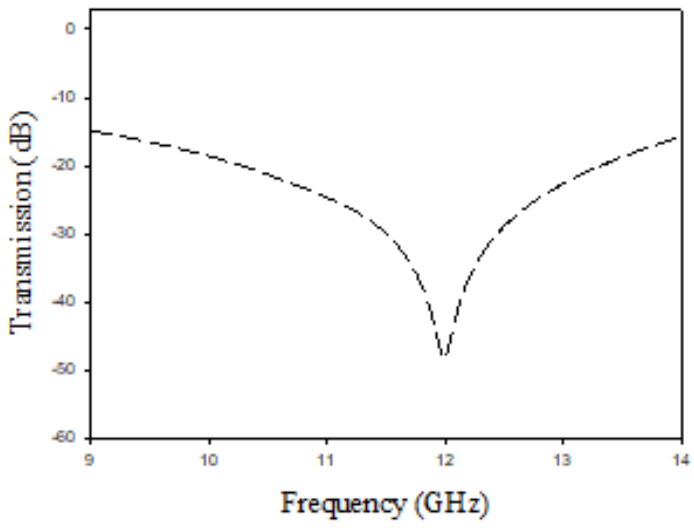

Figure 7. Transmission coefficient of a unit cell of FSS at $12 \mathrm{GHz}$

The return loss and gain of the designed trapezoid shaped antenna with the AMC and FSS are investigated. The performances of the antenna alone is Case 1, antenna with AMC as Case 2 and Case 3 is when the antenna integrated with AMC-FSS. In all cases, both AMC and AMC-FSS structures are arranged by $2 \times 3$ arrays and are positioned at the back of the antenna with $\lambda / 2.8 \approx 9 \mathrm{~mm}$ air gap. Figure 8 shows the arrangement of the antenna with AMC and AMC-FSS as they worked together. 


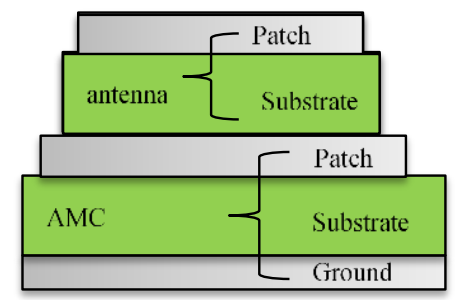

(a)

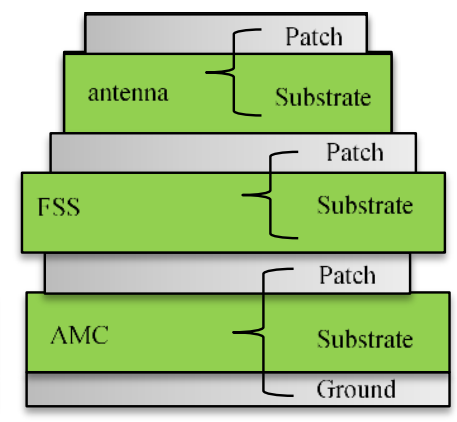

(b)

Figure 8. The layers configuration for (a) case 2 and (b) case 3

The return loss for 3 cases are plotted in Figure 9. Noted that the resonant frequency shifted to 12.35 $\mathrm{GHz}$ and $12.33 \mathrm{GHz}$ for Case 2 and case 3, respectively. Despite the shift in resonance, the antenna is still performed well at $12 \mathrm{GHz}$ with the return loss of -16.70 case 2 and the $-16.84 \mathrm{~dB}$ for case 3 . The bandwidth produced by case 1 is $1.29 \mathrm{GHz} \approx 10.79 \%$, meanwhile the bandwidth for case 2 is $13.95 \% \approx 1.72 \mathrm{GHz}$. On the other hand, the bandwidth for case 3 ranges from $11.51 \mathrm{GHz}$ to $13.24 \mathrm{GHz}$ giving a bandwidth of $14 \%$ approximately to $1.73 \mathrm{GHz}$. The enhancements of the trapezoid antenna radiation characteristics for three cases are summarized in Table 1.

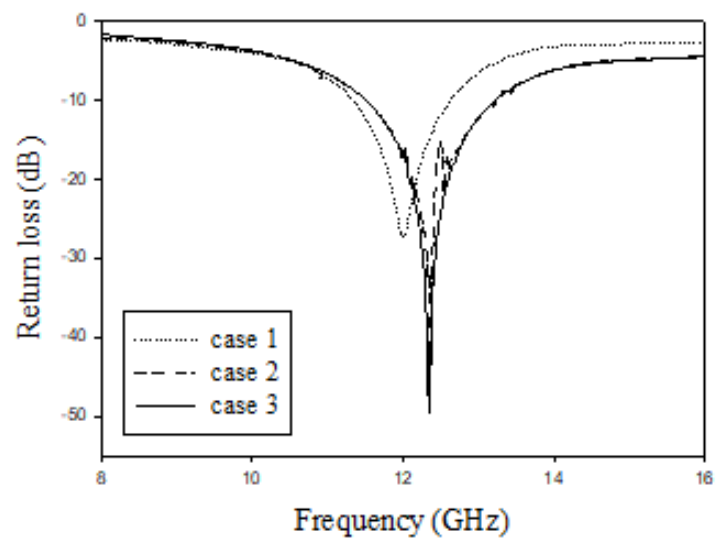

Figure 9. Return loss of the wideband antenna for 3 cases.

Case 3 produced the highest bandwidth and gain enhancement. Figure 10 shows the improvements of the radiation characteristics of the antenna for case 3 at $12 \mathrm{GHz}$. The radiation efficiency is $98.30 \%$, higher than the total efficiency, which is $96.21 \%$. Thus due to the mismatch loss which indicate how much of the signal is lost because of the line mismatch. The radiation pattern of the antenna for case 3 is directive patterns. Such forward directive pattern is appropriate for on body application since it minimizes the radiation that penetrates into the human.

However the return loss of the antenna alone is better compare to case 3 . The return loss of the antenna alone is $-27.35 \mathrm{~dB}$ meanwhile for case 3 is $-16.84 \mathrm{~dB}$ due to the mismatched during incorporation. Case 3 gives much improvements on the realized gain of the antenna which from $4.43 \mathrm{~dB}$ up to $6.74 \mathrm{~dB}$. Almost more than $50 \%$ gain enhancement since both of the AMC and FSS are acted as a good reflector for the antenna.

Table 1. Improvements of antenna radiation characteristics

\begin{tabular}{lccc}
\hline & Return loss $(\mathrm{dB})$ & Bandwidth $(\%)$ & Gain $(\mathrm{dB})$ \\
\hline Case 1 & -23.74 & 10.79 & 4.43 \\
Case 2 & -16.70 & 13.95 & 6.73 \\
Case 3 & -16.84 & 14.00 & 6.74 \\
\hline
\end{tabular}




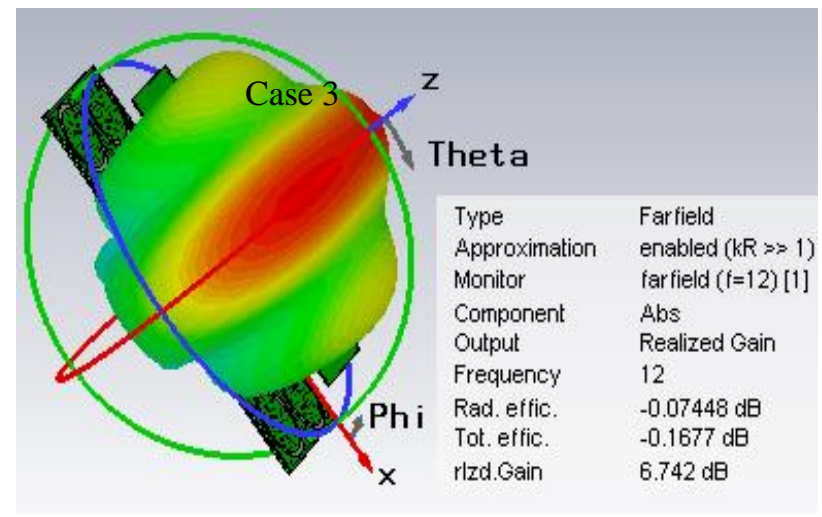

Figure 10. Radiation characteristics of the trapezoid antenna for case 3

\section{CONCLUSION}

The trapezoid antenna with Artificial Magnetic Conductor (AMC) and Frequency Selective Surface (FSS) are successfully designed on a $0.254 \mathrm{~mm}$ of RT/Duroid 5880 high frequency laminate. Three cases are analyzed; antenna alone, antenna with AMC and antenna with AMC-FSS. The 2x3 arrays of AMC and AMC-FSS were positioned at the back of the antenna with $6 \mathrm{~mm}$ air gap. The antenna works at $12 \mathrm{GHz}$, shifted shifted to $12.35 \mathrm{GHz}$ and $12.33 \mathrm{GHz}$ for case 2 and case 3, respectively. Despite the shift in resonance, the antenna is still performed well at $12 \mathrm{GHz}$ with the return loss of $-16.70 \mathrm{~dB}$ for Case 2 and return loss of $-16.84 \mathrm{~dB}$ for case 3 . Case 3 effectively enhanced the gain of the antenna from $4.43 \mathrm{~dB}$ to 6.74 $\mathrm{dB}$ and contributed to a directive antenna which successfully reduced the radiation of the antenna that penetrates into human body as the antenna being applied on on-body applications.

\section{ACKNOWLEDGEMENTS}

The support of Universiti Teknikal Malaysia Melaka (UTeM) is greatly acknowledged. The research was funded by UTeM Zamalah Scheme.

\section{REFERENCES}

[1] W. Saadat, S. A. Raurale, G. A. Conway, J. M. Alliste, "User identification through wearable antenna characteristics at 2.45 GHz," 12th European Conference on Antennas and Propagation (EuCAP 2018), pp. 1-4, 2018.

[2] G. A. Casula, G. Montisci, G. Valente and G. Gatto, "A robust printed antenna for UHF wearable applications," IEEE Transaction on Antennas and Propagation, vol. 66, no. 8, pp. 4337-4342, 2018.

[3] M. A. A. Dahab, H. H. M. Ghouz and A. Z. A. Zaki, "High gain compact microstrip patch antenna for X-Band applications," International Journal of Antenna, vol. 2, no. 1, pp. 47-58, 2016.

[4] S. Bhattacharjee, et al, "Design of a miniaturized dual-band textile antenna using characteristic modal analysis for on-body applications," Journal of Electromagnetic Waves and Applications, vol. 32, no. 18, pp. 2415-2430, 2018.

[5] S. Bhattacharjee, S. Maity, S. R. B. Chaudhuri and M. Mitra, "A compact dual band dual polarized omnidirectional antenna for on body applications," IEEE Transactions on Antennas and Propagation, vol. 67, no. 8, pp. 5044-5053, 2019.

[6] T. A. J. Mary, S. Durai and S. Mistry, "Patch antenna using biocompatible insulation layer in wireless on-body sensor applications," Journal of Engineering Science and Technology Review, vol. 12, no. 1, pp. 99-103, 2019.

[7] A. Arif, M. Zubair, M. Ali, M. U. Khan and M. Q. Mehmood, "A Compact, low-profile fractal antenna for wearable on-body WBAN applications," IEEE Antennas and Wireless Propagation Letters, vol. 18, no. 5, pp. 981-985, 2019.

[8] S. Salous, H. Parrott, C. Constantinou, Y. Nechayev, "On body and on body to off body communication in the 60 GHz band for health monitoring scenarios," 12th European Conference on Antennas and Propagation (EuCAP 2018), pp. 72-74, 2018.

[9] M. Abu, H. Hassan, M. S. I. M. Zin and S. A. M. Ali, "Design of single-band geometric pattern artificial magnetic conductor," ARPN Journal of Engineering and Applied Sciences, vol. 11, no. 5, pp. 3184-3187, 2016.

[10] R. F. Munawwar, M. Abu and S. A. M. Ali, "8 connected brances AMC-EBG and FSS for circle connected dipole at $5.8 \mathrm{GHz}, "$ International Journal of Applied Engineering Research, vol. 11, no. 10, pp. 6932-6939, 2016.

[11] S. Hashemi and A. Abdolali, "Room shielding with frequency-selective surfaces for electromagnetic health application," International Journal of Microwave and Wireless Technologies, vol. 9, no. 2, pp. 291-298, 2017.

[12] S. S. S. Nasser, W. Liu and Z. N. Chen "Wide bandwidth and enhanced gain of a low-profile dipole antenna achieved by integrated suspended metasurface," IEEE Transactions on Antennas and Propagation, vol. 66, no. 3, pp. 1540-1544, 2018. 
[13] S. A. M. Ali, M. Abu and H. Hassan, "Dipole antenna backed by 8-CBU AMC-EBG and 8 CBU FSS at 5.8 GHz," Journal of Telecomunication, Electronic and and Computer Engineering (JTEC), vol. 8, no. 1, pp. 108-114, 2016.

[14] A. Maisarah and M. A. Siti Adlina, "Performances of an ultra-thin AMC and FSS for 5G applications," 2018 International Conference on Engineering, Applied Sciences, and Technology (ICEAST), pp. 1-4, 2018.

[15] M. A. Siti Adlina and A. Maisarah, "Performances of flexibel antenna with ultra-thin AMC and AMC with multi-layer FSS," 2018 International Conference on Engineering, Applied Sciences, and Technology (ICEAST), pp. 1-4, 2018.

[16] S. Sah, M. R. Thipathy and A. Mittal, "Multiband and miniaturized dual layer antenna incorporated with FSS and DGS," Advanced Electromagnetics (AEM) Journal, vol. 7, no. 1, pp. 1-6, 2018.

[17] M. Muhamad, M. Abu and Z. Zakaria, "Novel artificial magnetic conductor for 5G application," Indonesian Journal of Electrical Engineering and Computer Science, vol. 5, no. 3, pp. 636-642, 2017.

[18] A. Joshi and R. Singhal, "Gain enhancement in probe-fed hexagonal ultra wideband antenna using AMC reflector," Journal of Electromagnetic Waves and Applications, vol. 33, no. 9, pp. 1185-1196, 2019.

[19] Y. Ge, Y. J. Zhao and J. Q. Chen, "Wideband RCS Reduction and Gain Enhancement for a Patch Antenna with Broadband AMC Structure," Radio Engineering, vol. 2, no. 1, pp. 45-52, 2019.

[20] A. P. Volkov, V. V. Kakshin, I. Y. Ryzhov, K. V. Kozlov and A. Y. Grinev, "Wideband low-profile dual-polarized antenna with AMC reflector," Progress in Electromagnetics Research, vol. 88, pp 15-20, 2020.

[21] A. Alemaryeen and S. Noghanian, "On-body low-profile textile antenna with artificial magnetic conductor," IEEE Transactions on Antennas and Propagation, vol. 6, no. 6, pp. 3649-3656, 2019.

[22] M. E. Atrash, et al, "A wearable dual-band low profile high gain low SAR Antenna AMC-backed for WBAN applications," IEEE Transactions on Antennas and Propagation, vol. 67, no. 10, pp. 6378-6388, 2019.

[23] R. Mondal, P. Soni Reddy, D.C. Sarkar and P.P. Sarkar, "Compact ultra-wideband antenna: Improvement of gain and FBR across the entire bandwidth using FSS," IET Microwaves, Antennas and Propagation, vol. 14, no. 1, pp. 66-74, 2020.

[24] M. Simruni and S. Jam, "Design of high gain, wideband microstrip resonant cavity antenna using FSS superstrate with equivalent circuit model AEU," International Journal of Electronics and Communications, vol. 112, 2019.

[25] S. T. Van, O. H. Kwon, E. Jung, J. Park, B. Yu, K. Kim,J. Seo and K. C. Hwang, "A low-profile high-gain and wideband log-periodicmeandered dipole array antenna with a cascadedmulti-section artificial magnetic conductor structure," Sensors, vol. 19, no. 4404, pp. 1-12, 2019.

\section{BIOGRAPHIES OF AUTHORS}

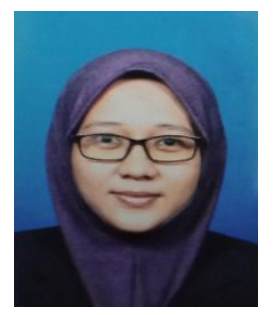

Siti Adlina Md Ali has received her Bachelor Degree in Electronic Engineering (Telecommunication) with honours in 2009 and Master of Science in Electronic Engineering in 2017 from Universiti Teknikal Malaysia Melaka. Now she is doing her Philosophy Degree $(\mathrm{PhD})$ at Universiti Teknikal Malaysia Melaka, analyzing losses introduced by microwave absorber starting from 2018.

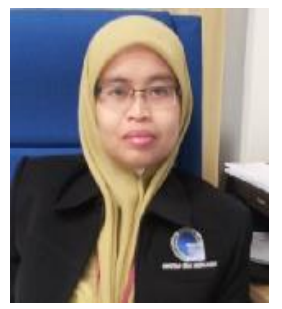

Maisarah Abu received her Bachelor Degree of Engineering in electrical engineering from Universiti Teknologi MARA in 2001. Then, she received her Master from Universiti Kebangsaan Malaysia in 2003. In 2012, she received her PhD from Universiti Teknologi Malaysia for her thesis on Dipole Antenna and Artifizial Magnetic Conductor for RFID Application. She was employed as a lecturer at Universiti Teknikal Malaysia Melaka since 2003. Now she is a Senior Lecturer with research interest of RF, Microwave and Antenna with Metamaterial (EBG, AMB, and FSS) and RFID.

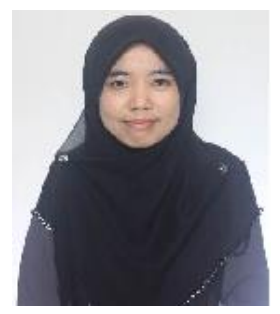

Siti Normi Zabri received her Bachelor Degree of Engineering in electrical engineering from Universiti Teknologi MARA in 2007. Then, she received her Master from The University of Sheffield in 2008. In 2015, she received her PhD from Queen's University of Belfast for her thesis on Study of Thin Resistively Loaded FSS based Microwave Absorbers. She was employed as a lecturer at Universiti Teknikal Malaysia Melaka with research interest of Frequency Selective Surface and Microwave Absorber. 